\title{
Grupo de Estudos e Pesquisas em Gestão e Financiamento da Educação (GEFIN): Algumas reflexões sobre sua constituição, processos e desafios
}

\author{
Group of Studies and Research in Management and Financing \\ of Education (Gefin): Some reflections about its constitution, \\ processes and challenges
}

\section{Rosana Gemaque ${ }^{1}$ \\ Dalva Valente Gutierrez ${ }^{2}$ Danielle Cristina de Brito Mendes ${ }^{3}$}

\section{Resumo:}

O texto trata da organização e do funcionamento do Grupo de Estudo em Gestão e Financiamento da Educação (GEFIN), do Instituto de Ciências da Educação da Universidade Federal do Pará, criado em 1998, com objetivo de investigar e aprofundar questões relacionadas à gestão e ao financiamento da educação por meio de um processo coletivo de formação. A intenção deste artigo é apresentar ideias para discussão e aprofundamentos sobre essa forma coletiva de formação e produção de conhecimentos. Para tanto, apresenta informações relativas à constituição do grupo, a dinâmica de organização, funcionamento e produções. Destaca aspectos positivos e as dificuldades e desafios na manutenção do Grupo. Por fim, avalia que apesar do aumento de atribuições para o docente-pesquisador decorrente do trabalho coletivo, o processo de formação e produção de conhecimentos na área de financiamento, em e por meio do Grupo vem consolidando-se como experiência promissora em tempos difíceis.

Palavras-chave: Educação. Grupo. Financiamento. Formação.

\begin{abstract}
:
This paper deals with the organization and functioning from the Study Group on Management and Financing of Education, of the Institute of Educational Sciences at Federal University of Pará, established in 1998, aiming at to investigate and deepen education management and funding problems through a collective process of formation and production of knowledge. In this regard, it is shown informations related to the constitution of the Group, its organizational dynamics, workings and academic production. It highlights positive aspects as well as the hardships and challenges to keep the Group. Finally, it evaluates that, even though the increase of attributions to the teaching staff as a result of the collective work, the formation and production process of knowledge in funding, inside the and through the Group has been consolidated as a promising experience in hard times.
\end{abstract}

Keywords: Education. Group. Funding. Formation

1Doutora em Educação. Professora do Instituto de Ciências da Educação da UFPA. Email: rgemaque@uol.com.br.

2 Doutora em Educação. Professora do Instituto de Ciências da Educação da UFPA. Email: dalva.valente@gmail.com.

3 Mestre em Educação. Professora da Rede de Ensino; membro do Gefin. 


\section{Introdução}

A produção de conhecimento e formação de pesquisadores por meio de Grupos de Pesquisa na área das Ciências Humanas destacou-se nos anos de 1990, com um crescimento significativo na década posterior, superior até aos das áreas mais tradicionais, como as de Ciências Biológicas e de Exatas. Estudos mostram que, de 2000 a 2006, o número de grupos de pesquisa no Brasil foi ampliado em 78,7\% e nas Ciências Humanas o aumento corresponde a 115,2\% (MOCELIN, 2009).

As explicações para esse crescimento são várias e polêmicas, variando em função da abordagem que orienta os estudos. Dentre elas são indicadas: a escassez de recursos financeiros para a pesquisa que estimulou os pesquisadores a buscarem estratégias para sua obtenção; o incremento de políticas públicas por meio das agências de fomento; o aumento da concorrência entre os pesquisadores diante da ampliação significativo do número de doutores.

O Grupo de Estudo em Gestão e Financiamento da Educação (GEFIN), do Instituto de Ciências da Educação da Universidade Federal do Pará, constituído em 1998, insere-se nesse contexto de expansão dos grupos de pesquisa. Sua origem e processos de consolidação refletem a conjuntura da produção de pesquisa no País, caracterizada pelo baixo investimento financeiro, no qual a distribuição de recursos é pautada por critérios de exigência de experiência, titulação e produção. Aliado a isso, encontra-se o interesse de um grupo de pesquisadores que visava a formar pessoas e fortalecer as investigações na área de financiamento da educação, cujas produções ainda eram escassas.

O objetivo deste texto é apresentar algumas ideias e discussões sobre a constituição e desenvolvimento de grupos de pesquisa a partir da experiência do GEFIN, considerando sua origem, desenvolvimento, organização, produtos e desafios.

Para tanto, as informações foram sistematizadas de modo a contemplar: 1- algumas discussões sobre a expansão dos grupos de pesquisa no Brasil, visando à contextualização do ponto de vista teórico; 2 - a Constituição do GEFIN, chamando atenção para a origem e as dinâmicas adotadas; a Organização e as dinâmicas de funcionamento; 3) os Produtos e desafios.

\section{Algumas considerações sobre a expansão de Grupos de Pesquisa}

Daniel Mocelin (2009) faz reflexões interessantes sobre a expansão dos grupos de pesquisa e, consequentemente, sobre a produção de conhecimento no Brasil. Para ele, essa expansão assenta-se teoricamente na compreensão de que vivemos tempos de transformações estruturais e culturais com rebatimentos em várias dimensões, dentre elas a educação, a ciência e seus produtores.

Apoiado em Castells (1996), o autor concebe que o núcleo do processo dessas transformações decorre de uma dupla lógica de redes e identidades. As redes constituídas por "instrumentalidade tecnológica e humana favorecem ação social em escala nunca antes imaginada" (p.36). A rede de identidades, por sua vez, ao entrelaçar os indivíduos à sua história, condições de vida, cultura potencializa suas formas de ação social. Acredita que as crises das instituições, assim como a sua reconstrução reside no centro dessas duas lógicas.

Nesse contexto de transformações estruturais, políticas e culturais as pesquisas em Ciência e Tecnologia ganharam destaque ao serem consideradas suporte de mudanças. Em função disso, demanda-se mais para a educação com o intuito de suprir as necessidades técnicas. Nas reflexões do autor, isso favoreceu ao crescimento do número de pesquisadores, cientistas e tecnólogos (MOCELIN, 2009).

Sobre isso, o autor destaca que

o número crescente de pesquisadores repercute, ao mesmo tempo, em maior desenvolvimento da produção científica e maior concorrência entre os pesquisadores, tanto por recursos quanto por reconhecimento e credibilidade. 0 próprio ambiente científico tornou-se mais 
complexo com a formação de uma massa crítica, com a ampliação do número de cursos e de alunos de pós-graduação e com novos agentes no campo científico, atingindo a lógica e o funcionamento de agências e de instituições voltadas para o conhecimento (p.36).

Reconhece que o aumento de pesquisadores decorre também de fatores institucionais tais como: mudanças na carreira docente; ampliação dos concursos; critérios de avaliação de projetos e de distribuição dos recursos; políticas de criação e avaliação dos cursos de pós-graduação e os critérios adotados, como a titulação de doutor para os docentes.

No que concerne à formação de grupos de pesquisa, Mocelin (2009) argumenta que, dos anos de 1990 a 2000, houve um destaque impulsionado, sobretudo, pela: alocação e escassez de recursos destinados à pesquisa; forma de distribuição de recursos que exige a constituição de grupo; livre formação de equipe por um pesquisador e alunos de graduação e de pós-graduação; afinidade temática; jogo de interesse, dentre outras.

Sem desconsiderar essas explicações, o autor sugere que o motivo central da expansão dos grupos de pesquisa decorre do aumento da concorrência no ambiente científico e da necessidade de aliança entre os pesquisadores, possibilitando melhor participação na distribuição dos recursos, sejam financeiros ou simbólicos. Trabalha com a hipótese de que "quanto maior o número de pesquisadores, mais aumenta a concorrência entre eles e maior é o número de alianças entre pesquisadores a fim de superar a condição de concorrência" (p.37). As consequências desse movimento são o surgimento de novas formas de atuação, de organização e de valores no ambiente científico e a contribuição na expansão da produção científica em termos bibliográficos, de linhas de pesquisa e de internacionalização.

Do ponto de vista teórico, o autor, apoiado em Weber, avalia a ocorrência de combinação entre as mudanças estruturais e as mudanças nas práticas dos atores sociais, de modo que "ambos os fenômenos se atrairiam mutuamente e parecem estar também atrelados a uma nova configuração da "comunidade científica", afetando sua organização, sua prática e o volume da produção científica nacional (p.37)". Todavia, ressalta tratar-se de uma tendência cuja explicação não tem a intenção de ser definitiva, geral ou exclusiva, reconhecendo assim outras possibilidades de explicação para as relações entre pesquisadores, grupos de pesquisas e órgãos de fomentos (nacionais e internacionais).

Assim sendo, argumenta que uma abordagem teórica importante e que tem orientado vários estudos sobre a temática, fundamenta-se no baixo grau de investimento financeiro em ciência e tecnologia no País, nos quais evidenciam as contradições que emergem dos discursos que advogam a importância da Ciência e da Tecnologia para o desenvolvimento nacional. Porém, defende que é igualmente importante o desenvolvimento de estudos apoiados em abordagens que enfatizam a perspectiva dos atores sociais, avaliando "como eles desenvolvem estratégias na tentativa de superar crises e dificuldades na busca por novos caminhos, novas oportunidades e novos cenários de luta (p.38)".

Embora não desconsidere o argumento de que as agências de fomento à Pesquisa, nacionais e internacionais, dentre elas a CAPES e CNPq, venham influenciando de forma importante o desenvolvimento da pesquisa e a expansão dos grupos, assim como explicando a relação entre eles, Mocelin (idem) avalia como intrigante os argumentos que consideram a formação de rede de pesquisadores decorrente, simplesmente, de uma política explícita dos agentes de fomento, pois essa posição recusa a possibilidades disso resultar de movimentos espontâneos das relações entre os pesquisadores.

Por fim o autor considera que

A formação de um grupo de pesquisa não decorre apenas de um encontro casual entre os pesquisadores, promovidos pelas oportunidades institucionais, mas em razão das novas condições do ambiente científico em que se encontram e de formas de afinidades, como, por exemplo, a temática. Fica evidente que muitas das referidas oportunidades são essenciais para o desenvolvimento cientííico e tecnológico do Brasil, mas chegar a essas oportunidades, em um contexto de maior concorrência, também sugere formas de organização e alianças entre os pesquisadores e estudantes iniciados no campo (p.39). 
Ao discutir as relações de poder como componente da ação dos atores sociais, Mocelin (idem) argumenta que é inegável que pesquisadores mais experientes tendem a provocar distorções na situação, tendo em vista que reúnem maiores possibilidades de captação de recursos.

Todavia, esse autor avalia que

Essa evidência, contudo, não implica conceber tais relações de forma determinantes, como se a desigualdade fosse definitiva. Não se nega que as relações de poder condicionam resultados no novo cenário, mas sugere-se que esse movimento é dialético: os agentes submetidos a tal condições tendem a reagir, buscando ou criando alternativas que podem transformar-se em oportunidades. Ou seja, a situação em que os agentes atuam é recursiva e não exclusivamente restritiva (p. 40).

Consideramos que essas ideias iniciais são importantes para suscitar reflexões em torno da constituição e manutenção dos grupos de pesquisas na área da educação e, de modo particular, na de financiamento da educação. É com este propositivo que fazemos uma incursão sobre e pelo GEFIN.

\section{Origem e Constituição do GEFIN}

O GEFIN foi constituído ao final dos anos de 1990 e estava vinculado, na época, ao Departamento de Administração e Planejamento da Educação, do Centro de Educação da Universidade Federal do Pará, tendo em vista que os proponentes não faziam parte da Pós-Graduação ainda em fase inicial, nesse contexto. Posteriormente, com a institucionalização da Pós-Graduação, a titulação de doutor, inserção de pesquisadores do Grupo nessa unidade e extinção dos departamentos no Centro de Educação, o Grupo passou a vincular-se a Pós-Graduação.

A origem do GEFIN aproxima-se do que Mocelin (2009) denominou de afinidade temática, considerando sua estreita relação com a implantação do Fundo de Manutenção e Desenvolvimento do Ensino Fundamental e Valorização do Magistério - FUNDEF.

A ideia de desenvolver estudos na área do financiamento da Educação no Centro de Educação, especificamente sobre o FUNDEF, foi possível mediante o incentivo da Professora Doutora Lisete Regina Gomes Arelaro, em 1997, pesquisadora experiente e reconhecida nacionalmente, vinculada a uma instituição de muito prestígio no Brasil - da Faculdade de Educação, da Universidade de São Paulo. O incentivo aos professores do Pará decorreu da intenção de discutir e elaborar um projeto de pesquisa que se destinaria a estudar o FUNDEF em nível nacional - ideia originada no Grupo de Trabalho Estado e Política Educacional, da Associação Nacional de Pós-Graduação e Pesquisa em Educação (ANPED).

Essa ideia foi se materializando a partir de uma reunião organizada e financiada pela Faculdade de Educação da USP, no período de 7 a 8 de dezembro de 1997, que contou com a participação de pesquisadores de outras universidades (UECE; UFPA; USP; PUC-SP; UERJ; UFRGS; UFMG; UFGR; UFPB; UFMA). Os pesquisadores atuavam na área de políticas educacionais e manifestavam interesse em aprofundar questões relacionadas à política de financiamento. Essa primeira reunião foi fundamental para o surgimento de uma rede de pesquisadores em financiamento da educação. Discutiram-se questões sobre: a operacionalização do projeto de pesquisa nacional que envolveria os pesquisadores dos Estados participantes e de outros a serem contactados; a criação de uma rede de pesquisadores sobre financiamento da educação; possíveis financiadores do Projeto. Assim, foi deliberado pela necessidade de constituição de grupos estaduais, os quais deveriam, inicialmente, buscar financiamentos nas e por meio de suas universidades.

A partir dessa reunião vislumbrou-se a concretização do projeto no Estado do Pará, tendo em vista a possibilidade de financiamento local com o apoio desses pesquisadores experientes e da possibilidade de formação e de titulação de professores para atuarem na área de financiamento da educação.

No $1^{\circ}$ semestre de 1998, as Pró-Reitorias de Pesquisa e Pós-Gradução e de Extensão da UFPA divulgaram um edital, abrindo inscrições para o financiamento de projetos que articulassem o ensino, a pesquisa e a 
extensão - PROINT. Diante disso, reunimos três professores do Departamento de Administração e Planejamento da Educação para a elaboração do Projeto de Pesquisa, a partir das orientações do grupo nacional. Os projetos de pesquisas dos grupos locais foram socializados para todos os Estados com a intenção de ajudá-los na elaboração e, ao mesmo tempo, visando a aproximações dos objetos de investigação, pois ainda não existia o "Projeto Nacional". Assim sendo, apresentamos e aprovamos o primeiro projeto do Grupo do Pará, intitulado Financiamento do Ensino Fundamental nos Municípios da Região Metropolitana de Belém - Um estudo da origem, do destino e do impacto dos recursos na gestão da educação e no processo de valorização do magistério, que envolveu os municípios de Ananindeua, Belém, Benevides, Marituba e Santa Bárbara do Pará.

Com a aprovação do referido Projeto conseguimos a adesão de mais uma Professora do Departamento de Fundamentos da Educação, de uma bolsista voluntária, aluna do Curso de Pedagogia e do Professor João Monlenvade, da Universidade Federal do Mato Grosso que, nesse período, vinha desenvolvendo estudo sobre o FUNDEF em municípios do Estado do Pará. Nesse início, o Grupo era formado por três professores com o título de Mestre, uma estudante de Pedagogia e um professor colaborador que atuava na função de consultor.

Embora o primeiro projeto tenha sido apresentado e aprovado em 1998, os recursos foram liberados somente em 1999. As dificuldades iniciais foram diversas, destacando-se: o acesso às receitas e despesas da educação; a falta de domínio de conceitos básicos sobre finanças públicas; escassez de recursos para operacionalização dos estudos.

No início de 2000 foi apresentado um novo projeto que ampliava a amostra para mais cinco municípios: Altamira, Cametá, Santarém, Soure e Marabá.

A partir de 2000, iniciou-se um processo de "dispersão" dos professores pesquisadores em função da necessidade de investimento na qualificação profissional, com vistas à obtenção do título de doutor, incentivado e exigido pela Universidade e pelos órgãos de financiamento das pesquisas. Nesse ano, a Professora coordenadora do Grupo deslocou-se para São Paulo para cursar o doutorado na FEUSP. Em julho, a coordenadora que a substituiu viajou para o Rio Grande do Sul com a mesma intenção. Nesse período, retornou ao DAPE uma professora que havia concluído o doutorado na PUC de São Paulo, na área de gestão e que assumiu o desafio de coordenar o Grupo a fim de dar continuidade às atividades. Em seguida, o terceiro membro do grupo se deslocou para Minas Gerais também para cursar o doutorado na UFMG.

Dessa fase inicial de existência do GEFIN apenas a primeira coordenadora continuou as atividades no Grupo. Os demais professores pesquisadores foram redefinindo seus objetos de investigação e inserindo-se em outros grupos. Porém, nesse caminhar inicial de formação novos docentes foram incorporados: um, que desde a realização do Curso de Mestrado já estava vinculada ao Grupo, com objeto de investigação dentro da temática aprofundada no GEFIN, e outro, que fazia parte desde a iniciação científica, ou seja, construiu a trajetória de pesquisa por meio do Grupo e, ao tornar-se docente e obter o título de doutor, continuou atuando e fortalecendo-o. Deste modo, avaliamos que no segundo momento de reconfiguração do Grupo, os vínculos dos docentes ficaram mais bem definidos.

\section{Organização e dinâmica de funcionamento}

Desde o início, a dinâmica de organização do GEFIN segue a natureza e demandas dos projetos em desenvolvimento. É aberto aos interessados e sempre que possível envolve nas pesquisas representantes do Sindicato dos Professores, diretores de escolas e professores. Em um dos projetos participaram os representantes das Associações dos municípios do Pará.

Em relação ao ensino, ofertávamos semestralmente uma disciplina eletiva para a graduação, com carga horária de 45 horas, intitulada Financiamento da educação no Brasil, a qual abordava questões relacionadas 
à origem, distribuição e controle dos recursos financeiros destinados à educação. Na nova proposta curricular do Curso de Pedagogia (2011) foi reivindicado pelos alunos que a mesma fosse incorporada ao currículo como disciplina obrigatória com carga horária ampliada para $60 \mathrm{~h}$.

Ainda em relação ao ensino, ofertávamos o Curso de Especialização em Políticas de Gestão e Financiamento da Educação. Sua oferta, porém, depende da disponibilidade dos docentes para coordená-lo. Foram ofertadas duas turmas que qualificaram cerca de 60 alunos. O curso é ainda muito solicitado pelos alunos e professores da rede, mas sua oferta e manutenção têm sobrecarregado os docentes responsáveis, tendo em vista que a prioridade de atuação docente no ensino é a Graduação e a Pós Graduação Stricto Senso. A oferta de cursos gratuitos de especialização na UFPA se dá por compromisso dos professores, uma vez que na maioria das Unidades os cursos são pagos.

Em relação à extensão, no primeiro projeto conseguimos realizar minicursos para conselheiros do Conselho de Acompanhamento e Controle Social do Fundef em municípios do Estado. Posteriormente, as atividades de extensão restringiram-se a palestras e consultorias em função do acúmulo de atividades dos pesquisadores.

A organização do trabalho do Grupo, embora direcionada pelas demandas do projeto em desenvolvimento, normalmente, adota a seguinte dinâmica: reuniões de planejamento semestrais com a participação de todos os envolvidos nos projetos e no Grupo; reuniões mensais com a finalidade de distribuir e avaliar as atividades de investigação e das demais atividades planejadas para o semestre; seminários de formação mensais com temáticas específicas do projeto em desenvolvimento, abertos ao público.

As atividades são realizadas no espaço ocupado pelo Grupo e funciona diariamente. Elaboramos cronogramas e calendários distribuindo os horários dos alunos da graduação e da pós-graduação de modo que sempre seja possível que a sala esteja com alguém para garantir o acesso dos alunos aos espaços, equipamentos e acervo bibliográfico.

Além dessas atividades, o grupo organiza eventos ou participa da organização juntamente com outros grupos de pesquisa da Pós-Graduação, envolvendo diretamente os alunos da Graduação e da Pós, oferecendo-Ihes a oportunidade de vivenciarem os processos de organização dos eventos e aprimorarem seus currículos. Além disso, são incentivados a apresentarem seus trabalhos. Ademais, os alunos participam da divulgação dos editais e do processo de seleção dos bolsistas, da elaboração dos novos projetos de pesquisa do grupo, atualização do Diretório de Pesquisa e o currículo lattes, atuam como monitores da disciplina de financiamento, enfim, contribuem fundamentalmente para a manutenção da rotina do grupo, ao mesmo tempo em que acumulam experiências no trabalho em grupo.

\section{Articulação do GEFIN com a rede de Pesquisadores de Financiamento da Educação}

Outra dinâmica de organização e manutenção do Grupo tem sido a articulação com grupos de pesquisadores locais de outras universidades. Isso tem possibilitado tanto a ampliação e manutenção dos docentes vinculados ao GEFIN quanto à garantia de infraestrutura, tendo em vista que o Instituto de Educação e a Pró-Reitoria de Pesquisa e Pós-Graduação da UFPA, há muito tempo, não têm destinado recursos para infraestrutura ou para a compra de material de expediente básico, tais como papel, tinta para impressora, envelopes. Deste modo, a articulação com outros grupos por meio de projetos com financiamento externo tem contribuído de forma decisiva para manutenção do grupo, assim como a concorrência por meio dos editais. Sobre isso, as hipóteses de Mocelin parecem pertinentes quanto ao aumento da concorrência entre os pesquisadores, principalmente em relação aos editais de financiamento dos projetos de pesquisas, visto que são mantidos por meio desses mecanismos.

O quadro 1 apresenta os Projetos desenvolvidos em rede, com professores de várias universidades, com financiamento e que contribuíram para a manutenção e consolidação do GEFIN. 
Quadro 1: Projetos desenvolvidos em rede envolvendo pesquisadores de outros Estados, de 2000 a 2012.

\begin{tabular}{|c|c|c|c|c|}
\hline Projetos de Pesquisa & Financ. & Universidade & Coord. Pará & Coord.Geral \\
\hline $\begin{array}{c}\text { Processo de implantação e } \\
\text { impacto do FUNDEF em Estados e } \\
\text { Municípios: casos e comparações } \\
\text { com vistas a uma avaliação } \\
\text { (2000/2012) }\end{array}$ & $\begin{array}{l}\text { ANPAE- } \\
\text { Fundação } \\
\text { FORD }\end{array}$ & $\begin{array}{l}\text { USP UFMA UFPA } \\
\text { UFPR UFPB UFPI } \\
\text { UFBA UFRGS UEC }\end{array}$ & $\begin{array}{l}\text { Prof }^{\mathrm{a}} \mathrm{Dr}^{\mathrm{a}} \\
\text { Rosana } \\
\text { Gemaque }\end{array}$ & $\begin{array}{c}\text { Prof }^{\mathrm{a}} \text { Dr }^{\mathrm{a}} \text { Lisete Arelaro (FEUSP); Prof } \\
\text { Dr. Romualdo P. de Oliveira (FEUSP); }^{\circ} \text {. } \\
\text { Prof }^{\mathrm{a}} \text { Dr }^{\mathrm{a}} \text { Beatriz Luce (UFGS); Prof }{ }^{\circ} \text { Dr. } \\
\text { Robert Verhine (UFBA) }\end{array}$ \\
\hline $\begin{array}{l}\text { Levantamento do Custo-aluno ano } \\
\text { em escolas da Educação Básica que } \\
\text { oferecem condições de um ensino } \\
\text { de qualidade }(2003 / 2004)\end{array}$ & INEP & $\begin{array}{l}\text { UFPA; UFPR; } \\
\text { UFGO; USP; UFPI; } \\
\text { UFBA; UFRGS }\end{array}$ & $\begin{array}{l}\text { Prof }^{\mathrm{a}} \mathrm{Dr}^{\mathrm{a}} \\
\text { Rosana } \\
\text { Gemaque }\end{array}$ & Prof $^{0}$ Dr José Marcelino Resende Pinto \\
\hline $\begin{array}{l}\text { Ensino médio noturno: registro e } \\
\text { análise de experiências em escola } \\
\text { no Estado do Pará (2003/2004) }\end{array}$ & $\begin{array}{l}\text { MEC- } \\
\text { UNESCO }\end{array}$ & $\begin{array}{l}\text { UFPA UFRN UFPB } \\
\text { UFMG UFSC FRGS } \\
\text { USP }\end{array}$ & $\begin{array}{l}\text { Prof }^{a} \text { Dr }^{\mathrm{a}} \\
\text { Rosana } \\
\text { Gemaque }\end{array}$ & $\begin{array}{l}\text { Prof }^{0} \text { Dr. Romulado P. de Oliveira } \\
\text { (FEUSP) } \\
\text { Prof }^{a} \text { Dr }^{\text {a }} \text { Sandra Zákia Lian Sousa } \\
\text { (FEUSP) }\end{array}$ \\
\hline $\begin{array}{c}\text { Remuneração de Professores de } \\
\text { Escolas públicas da Educação } \\
\text { Básica: configurações, impactos, } \\
\text { impasses e Perspectivas } \\
\text { (2008/2012) }\end{array}$ & $\begin{array}{l}\text { CAPES } \\
\text { INEP } \\
\text { SECAD }\end{array}$ & $\begin{array}{l}\text { UFPA UFRN UFPB } \\
\text { UEMG UFSC USP } \\
\text { UFRGS UFPR } \\
\text { UFPI }\end{array}$ & $\begin{array}{l}\text { Prof }^{a} \text { Dr }^{\mathrm{a}} \\
\text { Rosana } \\
\text { Gemaque }\end{array}$ & $\begin{array}{c}\text { Prof }^{0} \text { Dr. Rubens Barbosa de Camargo } \\
\text { (FEUSP) }\end{array}$ \\
\hline
\end{tabular}

Fonte: arquivos do GEFIN

O primeiro projeto desenvolvido em rede que o Grupo participou (2000/2002) foi muito importante para o seu surgimento e fortalecimento, uma vez que houve financiamento de recursos materiais, pagamento de passagens e diárias para participação nas reuniões gerais. Essas reuniões constituíam-se em momentos de formação em pesquisa em várias direções, tanto em termos de organização dos pesquisadores envolvidos quanto das questões metodológicas. Os encontros de pesquisadores experientes com os iniciantes ou de grupos consolidados com os que estavam começando ou em processo de consolidação possibilitaram a troca de experiência, sugestões, colaboração e consequentemente o estímulo para o surgimento de novos grupos estaduais e o fortalecimento dos que já existiam.

No período de realização desse primeiro projeto em rede pelo Grupo de financiamento, o GEFIN desenvolvia também projetos com financiamento local, incorporando bolsistas de Graduação em Pedagogia e realizando os primeiros eventos ampliados sobre financiamento da educação no Estado do Pará.

De 2003 a 2004, o Grupo participou de mais duas pesquisas desenvolvidas em rede nacional, coletando, sistematizando e analisando os dados relativos à situação do Estado do Pará. A primeira (2003-2004) referese ao estudo intitulado Ensino médio noturno: registros e análise de experiências, coordenado pelo Prof ${ }^{\circ} \mathrm{Dr}$ Romualdo Portela de Oliveira (FEUSP) e Profa Sandra Zákia Lian Sousa (FEUSP). Foi desenvolvido em 8 Estados (São Paulo; Pará; Paraíba; Goiás; Rio Grande do Norte; Minas Gerais; Paraná e Santa Catarina). Seu objetivo foi identificar, registrar e analisar experiências de ensino médio noturno que permitissem evidenciar fatores que vêm contribuindo para a concretização de um ensino de qualidade. A realização da referida pesquisa atendeu à demanda da Secretaria de Educação Média e Tecnológica (SEMTEC), do Ministério da Educação, com apoio da UNESCO, com a finalidade de subsidiar a formulação de políticas de melhoria do ensino médio no Brasil, particularmente aquele oferecido pela escola noturna. No Pará, o estudo contemplou 10 escolas que apresentaram os melhores índices de qualidade, localizadas nos municípios de Belém, Itaituba, Santarém, Abaetetuba, Igarapé-Miri e Ananindeua. A participação do GEFIN nesta pesquisa possibilitou a incorporação de novos membros (alunos e ex-alunos da Graduação e da Pós Graduação em Educação) e fortalecimento do trabalho coletivo com professores da área de políticas educacionais.

A segunda pesquisa (2003 a 2004) refere-se ao Levantamento do custo-aluno em escolas da educação básica que oferecem condições de um ensino de qualidade, coordenada pelos professores José Marcelino de Rezende Pinto (INEP) e Luiz Dourado (INEP). O referido estudo atendeu à demanda do INEP com a finalidade de 
estimar o custo-aluno de escolas públicas vistas como de qualidade, por disporem de instalações, equipamentos e demais insumos que as distinguiam das demais. Foi realizada em 10 Estados (Acre, Pará, Ceará, Bahia, Goiás, São Paulo, Minas Gerais, Paraná, Minas Gerais e Rio Grande do Sul). Nos Estados, foram contempladas 10 escolas vinculadas à rede pública de ensino, localizadas em áreas urbanas e rurais. No Pará, o estudo foi desenvolvido em 10 escolas localizadas nos municípios de: Belém, Paragominas, Ananindeua, Marabá e Santa Bárbara do Pará. A participação do GEFIN possibilitou o aprofundamento do financiamento no que concerne às questões do custo-aluno e também a aquisição de equipamentos e mobiliário.

Após quatro anos do término desses projetos, os pesquisadores da rede de financiamento da educação voltam a se articular para concorrer ao edital Observatório da Educação e têm aprovado o projeto intitulado Remuneração de Professores de Escolas públicas da Educação Básica; configurações, impactos, impasses e perspectivas, sob a coordenação geral do Profo Rubens Barbosa de Camargo. O objetivo do referido projeto é "analisar as configurações, os impactos, os impasses e as perspectivas decorrentes da implantação do Fundef, do Fundeb e do Piso Salarial Profissional Nacional na estrutura de remuneração dos professores da educação básica de 10 estados brasileiros no período de 1996 a 2012". O estudo, em desenvolvimento, vem sendo realizado em doze estados: São Paulo; Pará; Paraíba; Piauí; Paraná; Rio Grande do Norte; Minas Gerais; Santa Catarina; Rio Grande do Sul; Mato Grosso; Mato Grosso do Sul; Roraima, coordenados, localmente, por professores doutores de universidades. Envolve alunos de graduação e de pós-graduação e professores da educação básica, garantindo três bolsas por grupo estadual. Além desse apoio importante, repassa anualmente recursos para material de consumo, compra de material bibliográfico e financiamento de passagens e diárias para que membros dos grupos locais possam participar das reuniões e seminários promovidos pela rede. Esse apoio tem sido fundamental para troca de experiência entre pesquisadores e alunos no que concerne à organização de trabalhos em grupo, desenvolvimento de metodologias, troca de material bibliográfico; publicações em grupo; participação em bancas de defesa de mestrado e doutorado, enfim, proporcionando o debate e aprofundamento de questões referentes aos planos de carreira e remuneração de professores da educação básica.

\section{Articulação com outros Grupos de Pesquisa e Projetos Locais}

O GEFIN se articula também com outros Grupos de Pesquisa do Programa de Pós-Graduação do ICED, por meio dos projetos de pesquisa e de intercâmbios, como apresentados no quadro 2.

\section{Quadro 2: Projetos e Programas desenvolvidos com a participação do GEFIN}

\begin{tabular}{|c|c|c|c|c|}
\hline PROJETOS & Período & Financ. & $\begin{array}{c}\text { Grupo de Pesquisa da } \\
\text { UFPA }\end{array}$ & COORD. NACIONAL \\
\hline $\begin{array}{l}\text { Programa de Cooperação Acadêmica } \\
\text { entre Grupos de Pesquisa } \\
\text { consolidado e Grupo não consolidado } \\
\text { - PROCAD }\end{array}$ & $2007 / 2009$ & CAPES & $\begin{array}{l}\text { GEPES } \\
\text { GEFIN }\end{array}$ & $\begin{array}{c}\text { Profo }^{0} \text { Dr. Cabral (UFRN); } \operatorname{Profa}^{\mathrm{a}} \operatorname{Dr}^{\mathrm{a}} \text { IIma } \\
\text { Nascimento (UFMA); Prof } \text { Dr }^{\mathrm{a}} \text { Vera Lúcia } \\
\text { Jacob Chaves }\end{array}$ \\
\hline $\begin{array}{c}\text { Observatório de Trabalho Docente - } \\
\text { CASADINHO }\end{array}$ & $2008 / 2010$ & CNPQ & $\begin{array}{l}\text { GESTRADO } \\
\text { GEFIN } \\
\text { OBSERVE }\end{array}$ & $\begin{array}{l}\text { Prof }{ }^{\mathrm{a}} \mathrm{Dr}^{\mathrm{a}} \text { Olgaíses Cabral Maués (ICED- } \\
\text { UFPA) } \\
\text { Prof }{ }^{\mathrm{a}} \mathrm{Dr}^{\mathrm{a}} \text { Dalila Andrade de Oliveira (FE- } \\
\text { UFMG) }\end{array}$ \\
\hline $\begin{array}{l}\text { Programa de Cooperação Acadêmica } \\
\text { entre Grupos de Pesquisa } \\
\text { consolidado e Grupo não consolidado } \\
\text { - PROCAD NF }\end{array}$ & $2009 / 2012$ & CAPES & $\begin{array}{l}\text { GESTRADO } \\
\text { GEPES } \\
\text { GEFIN } \\
\text { OBSERVE }\end{array}$ & $\begin{array}{c}\text { Prof }^{\mathrm{a}} \text { Dr }^{\mathrm{a}} \text { Olgaíses Cabral Maués (ICED- } \\
\text { UFPA) } \\
\text { Profa }{ }^{\mathrm{a}} \text { Dra Dalila Andrade de Oliveira (FE- } \\
\text { UFMG) }\end{array}$ \\
\hline $\begin{array}{l}\text { Políticas de Financiamento na } \\
\text { Expansão do Ensino Superior }\end{array}$ & $2008 / 2010$ & CNPQ & $\begin{array}{l}\text { GEPES } \\
\text { GEFIN }\end{array}$ & $\begin{array}{l}\text { Profa }{ }^{\text {Dra }} \text { Vera Lúcia Jacob Chaves } \\
\text { (UFPA); Nelson Cardoso Amaral (UFGO) }\end{array}$ \\
\hline
\end{tabular}

Fonte: arquivos do GEFIN 
O primeiro projeto, o Programa de Cooperação Acadêmica entre Grupos de Pesquisa consolidado e Grupo não consolidado - PROCAD - envolvendo a UFMA; a UFRN e a UFPA, sob a Coordenação Geral do $\operatorname{Prof}^{\circ}$ Dr. Antonio Cabral Neto (UFRN); Vera Lúcia Jacob Chaves (UFPA) e Prof ${ }^{a}$ Dr $^{\mathrm{a}}$ IIma Vieira do Nascimento, teve como objetivo desenvolver pesquisas com vista a contribuir para a consolidação do Programa de Pós-Graduação em Educação das instituições envolvidas. Dentre as atividades desenvolvidas no âmbito desse projeto destacamse: Seminários de avaliação de políticas públicas; publicação de livros e artigos; realização de missões dos docentes; organização de um observatório de públicas. A participação do GEFIN nesse Programa possibilitou missões de estudo e troca de experiência entre os professores dos três Programas de Pós-Graduação e publicações de artigos e de capítulos de livros

O projeto Observatório de Trabalho Docente - CASADINHO - Financiado pelo CNPQ é coordenado pelas Professoras Olgaíses Maués (ICED-UFPA) e Dalila Andrade Oliveira (FE-UFMG). O objetivo é contribuir especificamente para a consolidação do Programa de Pós-Graduação em Educação da UFPA, mediante o desenvolvimento de ações conjuntas com o Programa de Pós-Graduação da Faculdade de Educação da UFMG, com vistas ao fortalecimento das ações dos Grupos de Pesquisa do PPGED-UFPA. O projeto financiou a aquisição de equipamentos e pagamento de serviços para o GEFIN e, juntamente com o PROCAD, possibilitou a realização de dois Seminários Internacionais. O primeiro ocorreu no período de 14 a 18 de junho de 2010 com o tema Políticas Educacionais e Trabalho Docente: Perspectivas comparadas, cujo objetivo foi apresentar, analisar, debater e avaliar políticas educacionais do Brasil, Argentina, Equador, Chile e da França, buscando conhecer e comparar essas ações e construir referenciais e possibilidades de ampliação de parcerias para o desenvolvimento de atividades conjuntas. O segundo Seminário Internacional foi realizado de 04 a 05 de dezembro de $2010 \mathrm{com}$ o tema Política Educacional e Trabalho Docente: avaliação e privatização do conhecimento. O objetivo foi "socializar diferentes experiências sobre a temática 'Trabalho Docente' por pesquisadores do Brasil, da América Latina e da Europa". Contou com a participação de pesquisadores do México, Argentina, Chile e Portugal e também de pesquisadores de universidades do Brasil como UNIMEP, UFSC e UFMG.

O Programa de Cooperação Acadêmica entre Grupos de Pesquisa consolidado e Grupo não consolidado - PROCAD NF, financiado pela CAPES, compreendeu uma parceria entre a UFPA e a UFMG, coordenado pelas Professoras Dra. Olgaíses Maués (ICED-UFPA) e Dra. Dalila Andrade Oliveira (FEUFMG). A temática deste programa também foi o "Trabalho Docente" e teve como objetivo possibilitar a troca de experiências entre docentes e discentes pertencentes aos grupos de pesquisa vinculados aos programas de Pós-Graduação das universidades envolvidas. Financiou bolsas de estudo e de missões de trabalho para alunos e professores, respectivamente. Além disso, financiou bolsa de pós-doutorado para professores do Programa.

O projeto de pesquisa Políticas de Financiamento na Expansão do Ensino Superior - Financiado pelos CNPq, coordenado pela Professora Dra. Vera Jacob Chaves e com vigência de 2009 a 2011, teve como objetivo geral "examinar como a evolução/involução do financiamento da educação superior, no período pós-LDB/1996, relaciona-se com a expansão e a efetiva reforma da educação superior, e como revela e questiona as contradições das políticas públicas, assim como o ajuste neoliberal da economia e da reforma do aparelho do Estado no Brasil". Este projeto "é parte do Projeto Integrado da Rede de Pesquisa UNIVERSITAS/BR que objetiva investigar de maneira mais geral o fenômeno da expansão da educação superior no Brasil, pós-1996, considerando os seguintes aspectos: Financiamento na expansão da educação superior; Organização institucional e acadêmica na expansão da educação superior; Avaliação na expansão da educação superior; Trabalho docente na expansão da educação superior; Acesso e permanência na expansão da educação superior; Produção do conhecimento na expansão da educação superior". 


\section{Produtos}

No decorrer do período de 1999 a 2012, o GEFIN conseguiu desenvolver várias atividades e produzir um quantitativo importante de material sobre o financiamento da educação que têm contribuído para compreender de forma mais aprofundada essa temática no contexto do Estado.

Dentre esses produtos destacamos os projetos de pesquisa desenvolvidos pelos docentes com o apoio dos alunos da Graduação em Pedagogia e de alunos da Pós-Graduação em Educação, como pode ser observado no quadro 3.

\section{Quadro 3: Projetos de Pesquisa Específicos do Grupo, de 1999 a 2012}

\begin{tabular}{|c|c|c|c|}
\hline PESQUISAS & PERÍODO & COORD. & FINAN \\
\hline $\begin{array}{c}\text { Financiamento do Ensino Fundamental nos Municípios da Região } \\
\text { Metropolitana de Belém - Um estudo da origem, do destino e do } \\
\text { impacto dos recursos na gestão da educação e no processo de } \\
\text { valorização do magistério. }\end{array}$ & $\begin{array}{l}1998 / 1999 \\
1999 / 2000\end{array}$ & $\begin{array}{l}\text { Profa Ms Rosana } \\
\text { Gemaque }\end{array}$ & $\begin{array}{l}\text { PROINT } \\
\text { UFPA }\end{array}$ \\
\hline $\begin{array}{l}\text { Financiamento da Educação em Municípios das Mesorregiões do } \\
\text { Estado do Pará - Um Estudo do Impacto do FUNDEF na Gestão e na } \\
\text { Valorização do Magistério }\end{array}$ & $2000 / 2001$ & $\begin{array}{l}\text { Prof }^{\mathrm{a}} \text { Ms Janaina } \\
\text { Spchet Menezes }\end{array}$ & $\begin{array}{l}\text { PROINT } \\
\text { UFPA }\end{array}$ \\
\hline $\begin{array}{l}\text { A qualidade da educação e a influência do FUNDEF na sua } \\
\text { construção }\end{array}$ & $2001 / 2002$ & $\begin{array}{l}\text { Prof }^{\mathrm{a}} \mathrm{Dr}^{\mathrm{a}} \text { Ney } \\
\text { Cristina Oliveira }\end{array}$ & $\begin{array}{l}\text { PARD } \\
\text { UFPA }\end{array}$ \\
\hline $\begin{array}{l}\text { Atendimento às matrículas da Educação Básica e Capacidade de } \\
\text { Financiamento dos Municípios do Estado do Pará - AMCF }\end{array}$ & $2005 / 2007$ & $\begin{array}{l}\text { Prof }{ }^{a} \operatorname{Dr}^{\mathrm{a}} \text { Rosana } \\
\text { Gemaque }\end{array}$ & CNPQ - PARD/UFPA \\
\hline $\begin{array}{c}\text { Acompanhamento e Avaliação do Processo de Implantação do } \\
\text { Fundo de Manutenção e Desenvolvimento da Educação Básica e de } \\
\text { Valorização dos Profissionais da Educação - FUNDEB - no Estado } \\
\text { do Pará }\end{array}$ & $2007 / 2010$ & $\begin{array}{l}\text { Prof }^{a} \text { Dr }{ }^{\mathrm{a}} \text { Rosana } \\
\text { Gemaque }\end{array}$ & Sem financiamento \\
\hline $\begin{array}{l}\text { A Política de Financiamento da Educação Básica no Município de } \\
\text { Barcarena: Implicações para a democratização educacional por meio } \\
\text { da valorização dos profissionais do magistério }\end{array}$ & $2011 / 2012$ & $\begin{array}{l}\text { Prof }^{\mathrm{a}} \mathrm{Dr}^{\mathrm{a}} \text { Dalva } \\
\quad \text { Gutierrez }\end{array}$ & PARD \\
\hline $\begin{array}{c}\text { Política de Valorização do Magistério da Educação Básica no } \\
\text { contexto recente da política de fundos em municípios da Região } \\
\text { Metropolitana de Belém: uma análise de carreira docente em } \\
\text { Ananindeua e Marituba. }\end{array}$ & $2012 / 2013$ & $\begin{array}{l}\text { Prof }{ }^{0} \text { Dr Fabricio } \\
\text { Aarão Carvalho }\end{array}$ & Sem financiamento \\
\hline
\end{tabular}

Fonte: Arquivos do GEFIN

Os três primeiros projetos de pesquisa são produtos do processo inicial de formação do Grupo e foram desenvolvidos com recursos da UFPA por meio dos seguintes programas: Programa Integrado de Ensino Pesquisa e Extensão-PROINT e Programa de Apoio ao recém-doutor - PARD.

No segundo semestre de 2004, os projetos específicos do Grupo são reativados com o retorno do Doutorado da Profa Dra. Rosana Gemaque. Portadora do título de Doutor passou a concorrer aos editais externos. Deste modo, aprovamos o projeto de Pesquisa intitulado Atendimento às matrículas da Educação Básica e Capacidade de Financiamento dos Municípios do Estado do Pará. O referido estudo teve como objetivo avaliar a política de municipalização do ensino do Pará e foi financiado pelo CNPq e pelo Programa de Apoio ao Recém-Doutor PARD/UFPA (2005/2007). Contou com a participação de representantes da Federação dos municípios paraenses e do Sindicato dos Professores do Estado do Pará (SINTEP). Nesse mesmo período ocorreu a vinculação do Grupo ao Programa de Pós-Graduação do Centro de Educação. O projeto funcionou como um "guarda-chuva", aglutinando subprojetos transformados em Dissertações de Mestrado, Monografias de Curso de Especialização e Trabalho de Conclusão de Curso de alunos de Graduação e Pós-Graduação. 
Posteriormente, o Grupo desenvolveu o Projeto de Pesquisa Acompanhamento e Avaliação do Processo de Implantação do Fundo de Manutenção e Desenvolvimento da Educação Básica e de Valorização dos Profissionais da Educação - FUNDEB - no Estado do Pará. O projeto teve como objetivo "acompanhar o processo de implantação do FUNDEB e avaliar suas tendências, comparando-as com os resultados do FUNDEF, em relação: ao gasto-aluno/ano; à dinâmica das matrículas da educação básica; ao controle social dos recursos; e a política de valorização do magistério", no período de 2007 a 2010. Não recebeu financiamento interno e externo e contou com os recursos e equipamentos existentes no GEFIN e recursos advindos dos outros Programas: PROCAD e CASADINHO.

O Projeto A Política de Financiamento da Educação Básica no Município de Barcarena: Implicações para a democratização educacional por meio da valorização dos profissionais do magistério, em desenvolvimento, possui financiamento do PARD e é composto por dois bolsistas. Analisa se a política de financiamento do ensino Básico vem contribuindo para a democratização da educação no Município de Barcarena no que concerne à valorização dos profissionais do magistério.

Já o projeto Política de Valorização do Magistério da Educação Básica no contexto recente da política de fundos em municípios da Região Metropolitana de Belém: uma análise de carreira docente em Ananindeua e Marituba, também em desenvolvimento, não tem financiamento e possui dois bolsistas. Visa a desvelar em que medida a estrutura da carreira docente nos municípios de Ananindeua e Marituba são efetivas na atratividade, formação e remuneração dos professores da rede municipal de ensino. Todos esses projetos geram relatórios parciais e finais que são disponibilizados à comunidade acadêmica.

Outra ação/produto do GEFIN e que tem se revelado como um aspecto importantíssimo na sua manutenção é a inserção da formação dos alunos da Graduação e Pós-Graduação.

Tabela 1: $\mathrm{N}^{\circ}$ de alunos que participaram diretamente do GEFIN, de 1998-2012.

\begin{tabular}{|c|c|c|c|}
\hline PERÍODO & $\begin{array}{c}\text { Alunos Bolsistas - } \\
\text { Graduação }\end{array}$ & Alunos de Mestrado & $\begin{array}{l}\mathrm{N}^{0} \text { de Alunos de } \\
\text { Doutorado }\end{array}$ \\
\hline 1998-1999 & 01 & - & - \\
\hline $2000-2002$ & 02 & - & - \\
\hline $2000-2001$ & 02 & - & - \\
\hline $2001-2002$ & 04 & - & - \\
\hline $2005 / 2005$ & 04 & - & - \\
\hline $2005 / 2006$ & 02 & 01 & - \\
\hline $2006 / 2007$ & 01 & 02 & - \\
\hline $2008 / 2009$ & 02 & 02 & - \\
\hline $2009-2010$ & 01 & 02 & - \\
\hline $2010-2011$ & 02 & 03 & - \\
\hline $2010-2012$ & 01 & 02 & - \\
\hline 2011-2012 & 02 & 02 & 01 \\
\hline $2012-2013$ & 03 & - & - \\
\hline TOTAL & 27 & 14 & 01 \\
\hline TOTAL GERAL & & 42 & \\
\hline
\end{tabular}

Fonte: arquivos do GEFIN 
A inserção dos alunos de Graduação ao Grupo ocorre por meio de seleção quando se trata de bolsa de iniciação científica ou voluntariamente, adotando como critério ter cursado ou estar cursando a disciplina Financiamento da Educação no Brasil. Os alunos da Pós-Graduação, orientandos dos professores, passam, automaticamente, a fazer parte do Grupo e usar sua infraestrutura. O envolvimento dos participantes nas atividades varia em função do objeto de estudo, disponibilidade e interesse.

No que concerne às produções bibliográficas, orienta-se e prioriza-se a publicação em grupo considerandose que o desenvolvimento das atividades acontece dessa forma, mas ocorrem também as publicações individuais dos docentes e discentes.

O quantitativo e tipo de publicações vinculadas às atividades do Grupo podem ser observados na tabela 2:

Tabela 2: Quantitativo de Produções Bibliográficas vinculadas ao GEFIN, de 1999 a 2000.

\begin{tabular}{|c|c|c|}
\hline PRODUÇÕES BIBLIOGRÁFICAS & QUANTITATIVO & $\%$ \\
\hline ARTIGOS EM PERIÓDICOS & 29 & 11,5 \\
\hline LIVRO & 1 & 0,4 \\
\hline CAPÍTULOS DE LIVROS & 14 & 6,5 \\
\hline RELATÓRIOS DE PESQUISAS & 15 & 36,7 \\
\hline TRABALHOS COMPLETOS PUBLICADOS EM ANAIS DE EVENTOS & 93 & 6,0 \\
\hline COORDENAÇÃO E PARTICIPAÇÃO EM ORGANIZAÇÃO DE EVENTOS & 15 & 8,7 \\
\hline PALESTRAS & 22 & 2,4 \\
\hline CURSOS E Mini CurSOS & 6 & 1,2 \\
\hline TESES & 3 & 5,5 \\
\hline DISSERTAÇÕES & 14 & 7,5 \\
\hline MONOGRAFIAS & 19 & 8,3 \\
\hline TRABALHOS DE CONCLUSÃO DE CURSO & 21 & 100,0 \\
\hline
\end{tabular}

FONTE: Arquivos do GEFIN. Nota: não foi possível contabilizar todas as produções

\section{Considerações Finais - Desafios}

Por fim, destacamos as dificuldades para a manutenção e consolidação de um grupo que tem como intenção desenvolver atividades de pesquisa, ensino e extensão. Em relação às atividades de pesquisa avaliamos que uma das dificuldades reside na resistência da maioria dos alunos ingressantes em "mergulhar" nos meandros do financiamento da educação e suas interfaces com as finanças/orçamento públicas, contabilidade e política econômica. Observa-se que ainda que o objeto de estudo esteja diretamente voltado para o financiamento, o aluno o tangencia. Isso decorre da complexidade do tema e da necessidade de investimentos sistemáticos nas questões de ordem conceituais e metodológicas.

Outra dificuldade se apresenta no que concerne ao acesso aos dados de receita e despesas da educação detalhados de modo a possibilitar maior aprofundamento das questões. O nível de agregação das informações disponibilizadas nos sítios oficiais dificulta o aprofundamento das análises. O detalhamento das informações concentra-se nas secretarias de educação que, em geral, não disponibilizam facilmente. 
No que concerne à organização, as dificuldades iniciais no GEFIN decorreram da dispersão dos professores no processo de titulação. A maioria não retornou para atuar no Grupo. Os outros dois docentes que após titulação permaneceram desde a realização do Mestrado já tinham vínculo com área de financiamento. Os desafios consistem no processo de formação dos alunos da Pós e a possibilidade de ingresso na universidade para que o número de docente pesquisador possa ser ampliado.

Outra dificuldade também diz respeito à rotatividade dos alunos. A cada novo ingressante, inicia-se o processo de formação e o tempo que permanecem, em geral, é de um ano - bolsista da graduação e os mestrando passam dois anos. Alguns se identificam e retornam para Pós, outros ingressam no mercado de trabalho. Neste aspecto, o processo de formação é bem dinâmico. De outro lado, mesmo considerando essa rotatividade, a manutenção da rotina do grupo só é possível com a colaboração dos alunos, tendo em vista a intensificação do trabalho do professor pesquisador que atua na graduação e na pós: orientação de alunos da Graduação e da Pós; concorrência aos editais em busca de financiamento; coordenação de projetos com todas as tarefas que Ihe são inerentes; atuação no ensino de Graduação e Pós-Graduação; proferição de palestras; participação em bancas de qualificação e de defesas; coordenação de eventos; produção de artigos e ainda garantir a manutenção da rotina do Grupo.

Quanto às questões teóricas e a existência do GEFIN, consideramos que existem movimentos que ora se aproximam e ora se afastam das interpretações sobre a origem e manutenção dos Grupos de Pesquisa. Concordamos com Mocelin (2009) que essa forma de organização dos pesquisadores e de produção coletiva é decorrente e estimulada por mudanças de ordem estrutural e institucional, assim como de movimentos e ações dos sujeitos. O caminhar é dialético, portanto, contraditório e por isso rico e estimulante.

Avaliamos que o quantitativo de ações de pesquisa, formação, eventos, publicações realizadas pelo GEFIN, ao longo desses 14 anos, foi possível em função da articulação em rede com grupos e pesquisadores de outras universidades e também da UFPA. Esse movimento decorre de políticas estratégicas que visam a contemplar os grupos e pesquisadores e a aumentar a produção, mediante a escassez de recursos financeiros e a necessidade de maiores investimentos.

De fato, o aumento de pesquisadores doutores, dos grupos de pesquisas, das produções em diferentes direções é algo evidente e admirável, mas é fundamental observamos "às custas" de quem esses avanços vem ocorrendo. Neste ponto, consideramos que as discussões sobre a intensificação do trabalho docente nas universidades e as consequências disso para a saúde responde muitas indagações sobre esse resultado.

Nesse movimento intenso e em várias direções que os docentes pesquisadores das universidades estão imersos identificamos situações e movimentos contraditórios, positivos e negativos. Uma das contradições se revela na relação entre aumento da produção, dos grupos de pesquisa e do número de pesquisa e o aumento da concorrência entre os pesquisadores por recursos e prestígios, tal como argumentado por Mocelin (2009). De outro lado, observa-se, nesse movimento, a construção de laços de solidariedade entre pesquisadores, grupos de pesquisa que colaboram para a formação e consolidação de grupos de pesquisa na área. Avalio que a rede de financiamento da educação é ilustrativa desse tipo de relação, assim como as relações construídas entre o GEFIN e outros grupos de Pesquisas da Pós-Graduação em Educação da UFPA (GEPES- GESTRADO, OBSERVE), em que recursos, ações, produções são partilhadas e compartilhadas.

Avaliamos que o grande desafio para a manutenção dos grupos de pesquisa das universidades é garantir que sua natureza continue sendo acadêmica diante dos rumos da política governamental nacional para a Ciência e Tecnologia direcionado para a incorporação de mais uma dimensão valorativa: a competitividade. Isso significa aumentar a concorrência entre os pesquisadores e abrir sem precedentes os grupos de pesquisas para as empresas. 


\section{Referências Bibliográficas}

GRUPO DE ESTUDOS EM GESTÃO E FINANCIAMENTO DA EDUCAÇÃO-GEFIN - 10 anos de História Faculdade de Educação da Universidade Federal do Pará, Belém-Pará, 2008.

MOCELIN, D. G. Concorrência e Alianças entre pesquisadores: reflexões acerca da expansão de grupos de pesquisa dos anos 1990 aos 2000 no Brasil. In: Revista Brasileira de Pós-Graduação, Brasília, v.6, n 11-p. 3564, dezembro de 2009.

RAPINI, M. S. O Diretório dos Grupos de Pesquisa do CNPq e a interação Universidade-Empresa no Brasil: uma proposta metodológica de investigação. In: Economia Contemporânea. Rio de Janeiro, 11 (1): 99-117, janabril de 2007. 